and aggressive and who (we and Mrs $\mathrm{N}$ believe) should remain in hospital? He refuses medication (but is given some). The magistrate has adjourned the hearing for two months, rather than make an order for his immediate discharge. $\mathrm{Mr} \mathrm{N}$ is one of many.

Incidentally, Mr Justice Powell also determined in 1986 that anorexia nervosa and alcoholism are not mental illnesses.

Prince of Wales Hospital

Sydney, Australia

REFERENCES

'SNowdon, J. (1983) Alternative proposals for reform of mental health legislation in Australia. Medical Journal of Australia. 471-474.

${ }^{2}$ WALLACH, I. (1986) Mental health advocacy in New South Wales. In unpublished proceedings of Seminar: Medical and Legal Aspects of Current Mental Health Legislation. Institute of Criminology, University of Sydney.

\section{Medico-legal responsibilities of hospital managers}

DeAR SirS

I wish to write in support of the views expressed by $\mathrm{Dr}$ Evans (Bulletin, September 1987, 11, 312) relating to the precipitous closure of one of the wards in an old mental illness hospital well-known in the Mersey Region. I would like to expand on the issues regarding the new Griffiths style of management and the related medico-legal consequences which I foresee.

Firstly, it is bad management practice to have to 'sneak' through such a ward closure without prior consultation. From the manager's point of view this may solve the immediate problem of progressing towards a goal of bed run-down as part of a regional strategy but the longterm effects on the confidence of members of the multidisciplinary team and their future co-operation do not seem to have been carefully considered. Such a blinkered approach seems to be all too common from my limited contact with the new managerial style where the short-term solutions to such complicated problems are all too readily used. Part of this may be related to the fixed-term nature of such managerial contracts so that a longer term view is seldom taken of their management decisions.

There seems to be a new trend of imposed managerial solutions which often have deleterious clinical consequences for the health professionals who have to pick up the pieces afterwards. Yet I wonder if the managers have ever given careful consideration to their own medico-legal position? In the above scenario a patient could easily have attempted suicide, become seriously behaviourally disturbed or have had a relapse of his treated mental disorder-the decision for ward closure was not taken by the Responsible Medical Officer and would probably have been against his wishes. The Unit General Manager has implicitly taken over this responsibility by taking this decision into his own hands. This responsibility must surely also entail medico-legal responsibility should a claim for compensation be made by one of the patients concerned or his relatives (as the medical practitioner concerned was not involved in the ward closure).

From my own experience I have come across a situation where a ward was seriously under-staffed and numerous representations by the discipline concerned fell on deaf managerial ears. In another situation a telephone system was not just inadequate but dangerous as no emergency line was continuously available. A member of staff became seriously ill in this hospital (with no emergency medical facilities on site) and we were unable to get a line out for an emergency ambulance. Repeated representations to management produced no remedy to the situation. At this time I contacted the Medical Defence Union for advice. I was told that if the medical staff feel staffing level, resources or other working conditions are inadequate for good practice and repeated representations have been made to management, the medico-legal responsibility then rests with the managers for any resultant catastrophe. Such claims are very expensive to settle, and I wonder what effects these would have on any "savings" made. Perhaps a few such medico-legal encounters would exercise the minds (and consultation skills) of management most wonderfully!

S. P. J. LYNCH

Rainhill Hospital

Prescott, Merseyside

\section{Discharge of long-stay psychiatric patients}

\section{DEAR SIRS}

I read with interest the letter by Dr M. Evans (Bulletin, September 1987) regarding the effects of transferring longstay psychiatric patients between wards. Although often a routine procedure, such transfers are inadequately studied. Shugar, Smith et al in Toronto ${ }^{1}$ interviewed both patients and their relatives after such a ward relocation. They found substantial dissatisfaction: they especially complained that they had not had an adequate opportunity to influence the transfer decision.

Equally pertinent in the era of de-institutionalisation is the process of transfer from hospital. Abrahamson ${ }^{2}$ interviewed 60 patients at Goodmayes Hospital and found that they were equally divided between those wanting to remain in hospital, wanting to leave, and being undecided or unrealistic.

In part this may be attributable to inadequate information about hospital closure plans and alternative forms of accommodation. In a study of long-stay in-patients I am conducting at Cane Hill Hospital in Surrey, $75 \%$ did not report knowing of any plans to change their accommodation, and $55 \%$ expressed the desire to remain in hospital indefinitely. It is possible to view this reluctance of patients to leave hospital as, at least in part, a realistic judgement that unless and until community-based facilities are adequately provided, remaining in hospital may be preferable. The reports of patients who have been discharged without 